On estimation the iron, calculated as ferric oxide, amounted to 0.042 per cent. We found present also creatinine and glycogen so that there is no reason for doubting the bona fides of the preparation. It is claimed that the blood of the horse contains more iron in hæmoglobin than does that of the ox, whilst it is also urged that by the use of horseflesh the danger of infection by tuberculosis so prevalent amongst oxen is avoided. Clinical trials are quoted, in which it would appear that this preparation has been given with advantage in conditions of constitutional debility, as in tuberculosis and anæmia. 2. The stated composition of glyphospher was confirmed by our analysis. It is a liquid preparation containing the glycerophosphates of calcium, sodium, manganese, iron, and strychnine. The total solids amounted to 34.01 per cent. and the mineral matter to 2.49 per cent. 3. Crolas oil is the name given to a specially refined castor oil, which is as pure and tasteless as any we have examined. It gave normal physical constants and showed free acidity of only 1.08 in terms of oleic acid.

(1) METAFERRIN PREPARATIONS; AND (2) TRICALCOL.

(The Metaferrin Company, Elberfeld ; Germany Agencr, Reitmeyer and Co., 63, Crutched Friars, London, E.C.)

1. Metaferrin is an interesting combination of iron and protein and may be given as regards its iron in preference to the inorganic salts. According to our analysis it contains 11 per cent. of iron calculated as metal, $65 \cdot 10$ per cent. of protein, 2.5 per cent. of fat, 23.4 per cent. of mineral matter, and 9.0 per cent. of moisture. Arseno-metaferrin, as the name implies, contains arsenic in addition to iron, a statement we have verified. The product, it is said, is not disintegrated in the stomach but in the intestinal tract, and has been given with advantage over ordinary inorganic arsenical preparations. Again, iodo-metaferrin contains iodine associated with protein and iron. We had no diffculty in setting free the iodine. "Raumauxane" is another metaferrin compound prepared on the same lines but contains soluble albumins. The proteins amounted to 78.50 per cent. according to total nitrogen, the fat to 2.50 per cent., the mineral matter to 12.00 per cent., and the moisture to 7.00 per cent. It contained a notable amount of iron in organic combination. These preparations are of interest in presenting the various drugs indicated in association with organic elements. In this way some of the therapeutic difficulties in employing the elements in the inorganic form are removed. 2. Tricalcol is a combination of milk albumin with tricalcium phosphate, which is, curiously enough, more soluble in alkali than in acid. The phosphate of lime, which amounts to 20 per cent. - a claim which we have confirmed practically-is said to be present in the colloidal form. The phosphate of lime is readily absorbed. The analysis gave protein, 69.00 per cent. ; fat, 2.50 per cent. ; mineral matter, 18.90 per cent. ; and moisture, $9 \cdot 6$ per cent.

\section{IODEX SUPPOSITORIES.}

(Menley and James, Mendey House, Farringdon-road, LONDON, E.C.)

The employment of free iodine in rectal diseases claims attention. In the iodex suppository the iodine is associated with a neutral fatty base which melts at body temperature. That the iodine is present in the free state was shown by the fact that alcohol extracted it, the solution on being allowed to evaporate on starch paper giving the well-known blue reaction. The iodex suppository appears to be very convenient to use, and it is stated that owing to the association of the iodine with a bland fatty basis it possesses no ir itating or corrosive action, while it serves as an antiseptic and healing agent. The amount of iodine in each suppository is $\frac{3}{8} \mathrm{gr}$. The moulded cone is contained in a soluble gelatin envelope which preserves the iodine strength.

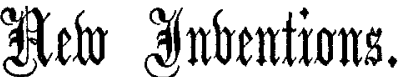

\section{CELLULOID INHALER}

THE accompanying illustration represents a celluloid inhaler which I have been using for some time. The diaphragm fixed across the middle of the inhaler contains ten cell-like chambers each with an aperture at the side and at the bottom, so arranged that any escape of fluid from the sponge into the lower half of the inhaler is impossible with ordinary care. The inhaler has also a lid perforated to admit a free current of air and to allow the sponge to be placed in situ. A fresh supply of the anæsthetic can be readily given by removing the lid. There is also a spout through which additional anæsthetic may be dropped without removing the inhaler from the

face. It is essential in all inhalers where a sponge is used that it should be of good absorbent quality.

The inhaler is made in three sizes and may be obtained at any surgical instrument makers.

C. J. OGLE, M.R.C.S. Eng., Anæsthetist to the National Dental Hospital and to Guy's Hospital, \&c.

\section{ROYAL COLLEGE OF SURGEONS OF ENGLAND.}

\section{Elemetion of Members of Council.}

A MeETrivg of Fellows was held on July 3rd at the College in Lincoln's Inn Fields to elect four members of Council. The result of the poll was as follows :-

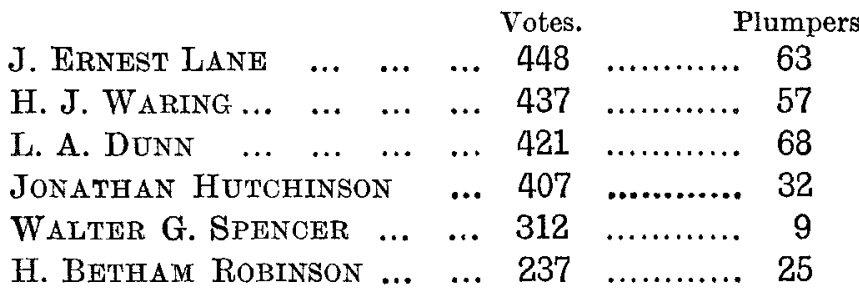

The President declared Mr. Lane, Mr. Waring, Mr. Dunn, and Mr. Hutchinson to be elected. The first two will hold office for the full period of eight years; Mr. Dunn as substitute member for Mr. Bruce Clarke will retire in 1915 ; and Mr. Hutchinson as substitute member for the late Mr. Clinton Dent will retire in 1919.

There were in all 872 votes recorded, of which 13 were votes given personally, while 859 votes were sent by post; but 7 of these voting papers were invalid, as for one reason or another they did not comply with the regulations

Grant to the Widow of Dr. Edward Adrian Wrison. - On July 7th the Mansion House Committee of the Captain Scott Fund decided to allot $£ 34,000$, out of the $£ 75,000$ collected, to the widows and relatives of those who lost their lives in Captain Scott's Expedition. These grants are, of course, in addition to the Government provision. The sum allotted to Mrs. Wilson is $£ 8500$. For the publication of the scientific results $£ 17,500$ is set aside. StaffSurgeon E. L. Atkinson, R.N., will represent the Scientific Staff of the British Antarctic Expedition on the publication committee of three. The other two members will be selected respectively by the Royal Society and the Royal Geographical Society. $£ 18,000$ will be expended on a memorial to Captain Scott and his comrades, and $£ 5100$ to settle the deficit on the expedition. 